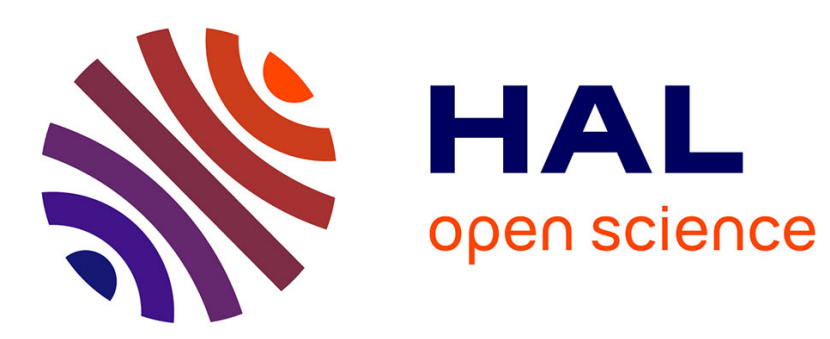

\title{
FERMI SURFACE TOPOLOGY OF V3Si MEASURED BY THE POSITRON ANNIHILATION TECHNIQUE
}

\author{
S. Samoilov, J. Ashkenazi, M. Weger, I. Goldberg
}

\section{To cite this version:}

S. Samoilov, J. Ashkenazi, M. Weger, I. Goldberg. FERMI SURFACE TOPOLOGY OF V3Si MEASURED BY THE POSITRON ANNIHILATION TECHNIQUE. Journal de Physique Colloques, 1978, 39 (C6), pp.C6-421-C6-423. 10.1051/jphyscol:19786189 . jpa-00217604

\section{HAL Id: jpa-00217604 https://hal.science/jpa-00217604}

Submitted on 1 Jan 1978

HAL is a multi-disciplinary open access archive for the deposit and dissemination of scientific research documents, whether they are published or not. The documents may come from teaching and research institutions in France or abroad, or from public or private research centers.
L'archive ouverte pluridisciplinaire HAL, est destinée au dépôt et à la diffusion de documents scientifiques de niveau recherche, publiés ou non, émanant des établissements d'enseignement et de recherche français ou étrangers, des laboratoires publics ou privés. 


\title{
FERMI SURFACE TOPOLOGY OF $V_{3} S$ I MEASURED BY THE POSITRON ANNIHILATION TECHNIQUE
}

\author{
S. Samoilov, J. Ashkenazi, M. Weger ${ }^{*}$ and I.B. Goldberg*
}

Département de Physique de la Matière Condensée, Université de Genève, Switzertand *The Racah Institute of Physics, The Hebrew University, Jerusalem, Israel

Résumé.- Une expérience d'annihilation de positrons dans le $\mathrm{V}_{3} \mathrm{Si}$ suivant la direction [100] est présentée, ainsi qu'un calcul théorique de la distribution des impulsions en espace $\vec{k}$ dans le schêma de zones étendues. Ce calcul a été fait dans 1'approximation de bandes indêpendantes. Il met en évidence l'existence de sections planes dans la surface de Fermi en accord avec la majorité des structures qui apparaissent dans la dérivée de la distribution des impulsions mesurée.

Abstract.- A positron annihilation experiment on $V_{3} \mathrm{Si}$ in the [100] direction is presented as well as a theoretical computation of the momentum distribution in $\vec{k}$ space in an extended zone scheme. This computation was done in the independent band approximation. It shows that the Fermi Surface contains planar sections in agreement with most of the structure appearing in the derivative of the measured momentum distribution.

We wish to report the experimental observation of sharp discontinuities in the momentum distribution (MD) of the conduction electrons in the high- $\mathrm{T}_{c}$ intermetallic compound $\mathrm{V}_{3} \mathrm{Si}$ by the method of positron annihilation. These sharp discontinuities are observed in the [100] direction indicating the possible existence of planar sections of the Fermi surface (FS) perpendicular to this direction. A planar section of the FS gives rise to discontinuities in the $M D$, hence to $\delta$-function singularities in its derivative. Therefore the positron annihilation technique should be suited ideally to detect such planar sections $/ 1 /$. However, we should note that the magnitude of the discontinuities in materials like $\mathrm{V}_{3} \mathrm{Si}$, with 38 conduction electrons per unit cell, should be rather small $/ 2 /$.

The $M D$ in the [100] direction was measured by $\gamma^{-} \gamma$ coincidences using a $25 \mathrm{mCi}{ }^{58} \mathrm{Co}$ positrons source and conventional long-slit NaI(T1) detectors with an angular resolution of $0.5 \mathrm{mrad}$. The moving detector was scanned over an angular width of $\pm 13 \mathrm{mrad}$. In the construction of the apparatus emphasis was placed on mechanical rigidity and stability using a high-precision $x-y$ table driven by a stepping motor to ensure precise reproductibility. The vertical setting of the $40 \mathrm{~cm}$ long slits was continuously verified to $1 / 4^{\prime}$ $1 / 2$ ' accuracy. The temperature of the $\mathrm{v}_{3} \mathrm{Si}$ single crystal was $77 \mathrm{~K}$.

The numerical derivative of the angular correlation curve (figure 1) was computed by diffe- rentiating a polynominal fit to each four consecutive experimental points, using polynominals of order 3 . It possesses several strong sharp maxima and minima.

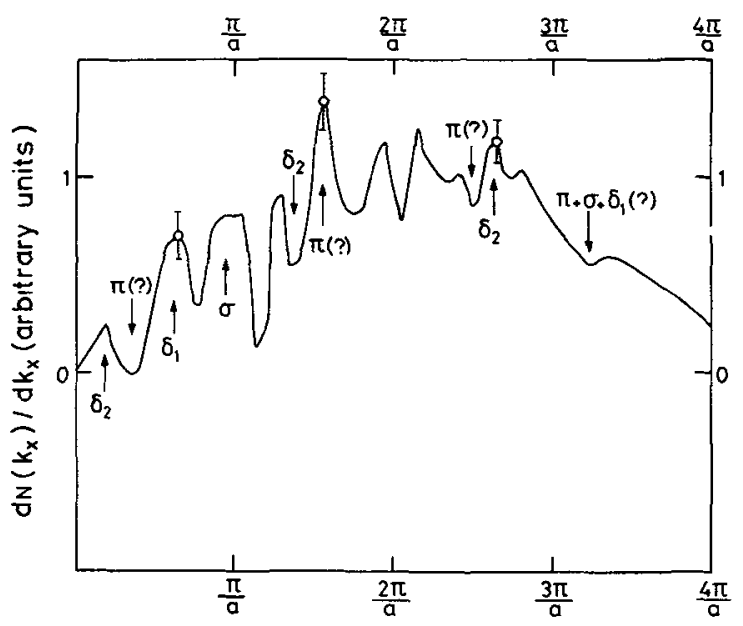

Fig. 1 : Derivative of the experimental angular correlation curve. Contributions from different bands are noted. The contributions of the $q$-band are uncertain as well as the structure in the 4th BZ.

Their width is limited by the experimental resolution of $0.5 \mathrm{mrad}$. This structure is remarkable and we believe that it is significant in view of the numerous statistical tests applied /2/ (detailed description will be given elsewhere). Since the band structure of $\mathrm{V}_{3} \mathrm{Si}$ is complicated, some approximation may be required at least 
for preliminary work. A useful one consists of regarding $\left|\mathrm{m}_{\ell}\right|$ as a good quantum number in zeroth order. Although states with a different $\left|m_{\ell}\right|$ value hybridize considerably $/ 3,4 /$, near the centre of the band where the Fermi level is located, states are pushed up and down, so that the net displacement of most states due to hybridization is about $0.5 \mathrm{eV}$. In this approximation (IBA), the $\sigma$-band $\left(\mathrm{m}_{\ell}=0 ; \mathrm{d}_{z^{2}}\right)$ consists of orbitals with lobes along the chains and conseruent $1 \mathrm{v}$ weak inter-chain counling, resulting in a nearlv nlanar FS. The $\delta_{2}$ band $\left(d_{x y}\right)$ has a large peak in the density of states due to states with $\Gamma^{\prime} 25, M_{5}, x_{3}$ symmetry, falling near the Fermi level. The $\delta_{1}$ band $\left(d_{x 2-y_{2}}\right)$ hybridizes strongly with the $S i 3 p$ band. The $\pi$ band $\left(\mathrm{m}_{\ell}= \pm 1 ; \mathrm{d}_{x z}\right)$ has a rather complicated structure. Under inversion it has symetric states at the top of the band, and antisymmetric ones at the bottom.

In the frame of the IBA we computed the $M D$ in $\vec{k}$ space in an extended zone scheme, over 125 Brillouin zones (BZ). Since our main interest is the structure appearing in the derivative momentum distribution (DMD), we coudd simplify the computation by : (a) assuming a constant wave function for the positron (b) in computing the band structure, tight binding basis functions were used for the $3 d$ electrons approximating the atomic (Wannier) $3 d$ basis functions by :

$\psi_{\mathrm{m}}^{3 \mathrm{~d}}(\overrightarrow{\mathrm{r}})=\mathrm{C}_{1} e^{-\alpha^{2} \mathrm{r}^{2} \mathrm{r}^{2}} \quad \mathrm{Y}_{2 \mathrm{~m}}(\hat{\mathrm{r}})$

Thus the Fourrier transforms needed for the computation of the MD are linear combinations of analytical expressions of the form :

$\tilde{\psi}_{\mathrm{m}}^{3 \mathrm{~d}}(\overrightarrow{\mathrm{p}})=\mathrm{C}_{2} \mathrm{e}^{-\mathrm{p}^{2} / 4 \alpha^{2}} \mathrm{p}^{2} \mathrm{Y}_{2 \mathrm{~m}}(\hat{\mathrm{p}})$

Such a parametrization of the wave functions avoided computer time consuming numerical integrations. The computation was done on each' sub-band separately, neglecting hybridization. The Fermi level was scanned through the whole width of the band, the aim being to reveal structures in the DMD in accordance with the experimental ones.

This band structure predicts for the $\sigma$-band a reasonably planar FS yielding a positive peak in the DMD as observed at $0.95 \pi / a$, and a negative peak at $3.05 \pi / a$ not observed, probably due to lack of statistical accuracy in this region. Note that hybridization may have strong effects on the FS of this band.

As for the $\delta_{2}$ band, since the transfer- integral between next-nearest neighbours ( $0.4 \mathrm{eV}$ ) is as large as the one between nearest neighbours $(20.5 \mathrm{eV})$, we cannot expect a planar FS extending over most of the $B Z$ but "torn out planes" $/ 3 /$. The computation was performed for several values of $\varepsilon_{F}-\varepsilon\left(\Gamma^{\prime}{ }_{25}\right)$ and of $J\left(\delta_{2}\right)$ (two-centre integrals between nearest neighbours). It turns out that the structure in the DMD is essentially the same for $-0.58 \mathrm{eV} \leq \mathrm{J}\left(\delta_{2}\right) \leq-0.38 \mathrm{eV}$, but is crucially determined by the position of the $\Gamma^{\prime} 25$ level. For $\varepsilon_{F}-\varepsilon\left(\Gamma^{\prime} 25\right)=0.25 \mathrm{eV}$ the maximum in the experimental derivative at $0.2 \pi / a$, the minimum at $\frac{4}{3} \cdot \frac{\pi}{a}$ and the maximum at $\frac{8}{3} \cdot \frac{\pi}{a}$ may be attributed to this band. This position of the $\delta_{2}$ band is in agreement with previous theoretical calculations /3/ though not with orders /4/ which yield about $0.7 \mathrm{eV}$. As long as hybridization with other bands splits the degenerate states $\Gamma^{\prime} 25, M_{5}, X_{3}$ by less than $0.5 \mathrm{eV}$ we should not expect radical changes of this $M D$.

In previous theoretical calculations /3/

the $\Gamma_{12}$ state of the $\delta_{1}-p$ band is slightly

above the Fermi level. In computing the MD a possible way to account for the peak in the derivative at $0.6 \pi / a$ is by puacing the $\Gamma_{12}$ state at the Fermi level $\left(0 \leq \varepsilon_{F}-\varepsilon\left(\Gamma_{12}\right) \leq 0.1 \mathrm{eV}\right)$. The $\pi$ band is very complicated. If the $\Gamma_{15}$ level is near the Fermi level ( $n_{\pi} \approx 2$ electrons/V atom), a minimum at $\pi / a$ and a maximum at $3 \pi / a$ should appear in the $D M D$, which might be masked by the corresponding sharp maximum and minimum due to the $\sigma$-band. But we should note that the $\Gamma_{15}$ state hybridizes strongly with the $S i 3 p$ and the shift due to this hybridization may amount to $1.5 \mathrm{eV} / 3 /$. This hybridization manifests itself in the electronic density measured by $x$-ray /5/ which shows strong maxima between the $\mathrm{Si}$ and the centre of the $\mathrm{V}-\mathrm{V}$ bonds (where both the $\Gamma_{15} \mathrm{~V}, 3 \mathrm{~d} \uparrow$ and $\mathrm{Si} 3 \mathrm{p}$ orbitals have a maximum). A charge transfer from $S i$ to $V$ suggests indeed a larger occupation of the $\mathbb{R}$-band. In the IBA, for $n_{\pi} \simeq 3$ electrons $/ V$ atom, we can attribute the minimum at $0.4 \pi / a$, the strong maximum at $1.55 \pi / a$, the minimum at $2.45 \pi / a$ and the maximum at $3.55 \pi / a$ to this band. It is hard to believe that such a high occupation is realistic and this results suggests that a self consistent calculation is needed.

We presented in this work an experimental evidence concerning the possible existence of planar sections of the $F S$ in $V_{3} S i$ perpendicular to the [100] direction. We computed, naively, the 
momentum distribution in $\vec{k}$ space on the basis of the coupled linear chains model. It turns out that this simple minded picture, which was heavily criticized $14 /$, has the merit of providing plausible explanation, at least qualitatively, of most of the structure appearing in the derivative of the experimental momentum distribution.

Lately, a new APW band structure calculation for $\mathrm{Nb}_{3} \mathrm{Sn}$ was performed $/ 6 /$. In this calculation non muffin-tin corrections were included inside and outside the muffin-tin spheres due to the special topological arrangement of the atoms in the unit cell. Consequently planar sections of the FS, perpendicular to the [100] direction appear, due to the $\delta_{1}$ band, in agreement with the observed peak at $0.6 \pi / \mathrm{a}$ in the $\mathrm{DMD}$.

\section{References}

/1/ Berko, S. and Weger, M., Phys. Rev. Lett. 24 (1970) 55; Computational Solid State Phys. (Plenum Press, New York) 1972.

/2/ Samoilov, S. and Weger, M., Solid State Commun. 24 (1977) 821.

/3/ Weger, M., Rev. Mod. Phys. 36 (1964) 175; Weger, M. and Goldberg, I.B., Solid State Phys. 28 (1973) $1-177$.

14/ Mattheiss, L.F., Phys. Rev. B12 (1975) 2161.

/5/ Staudenmann, J.L., Coppens, P., and Mu1ler,J., Solid State Commun. 19 (1976) 29.

/6/ Van Kesse1, A.T., Myron, H.W. and Mue1ler,F.M. to be published. 